\title{
Administración satisfactoria de la vacuna triple viral mediante una prueba de provocación gradual en una paciente con anafilaxia después de una vacunación previa Successful administration of measles-rubella-mumps vaccine by graded challenge in a case with anaphylaxis after prior vaccination
}

\author{
Dra. Tuba Tuncel ${ }^{a}$, Dra. Ozlem Sancaklib y Dra. Ece Ozdogru ${ }^{b}$
}

\begin{abstract}
RESUMEN
La alergia al huevo es una de las alergias alimentarias más frecuentes durante la niñez, junto con la alergia a la leche de vaca. La vacuna triple viral (VTV), contra el sarampión, la rubéola y las paperas, es parte del calendario de vacunación pediátrica y contiene proteína de huevo. La recomendación aceptada en la actualidad es que la VTV debe administrarse en una sola dosis y bajo supervisión médica en los pacientes con alergia al huevo. Si bien se ha informado que la VTV es segura para estos pacientes, algunos tuvieron anafilaxia. En general, la anafilaxia después de una vacunación previa se considera una contraindicación. En este artículo, presentamos el caso de la administración satisfactoria de la VTV mediante el incremento gradual de la dosis a una paciente que tuvo anafilaxia después de una vacunación previa.

Palabrasclave:anafilaxia, niño, alergiaal huevo, vacuna tripleviral.
\end{abstract}

http:/ /dx.doi.org/10.5546/aap.2017.e89

Texto completo en inglés: http:/ /dx.doi.org/10.5546/aap.2017.eng.e89

Cómo citar: Tuncel T, Sancakli O, Ozdogru E. Administración satisfactoria de la vacuna triple viral mediante una prueba de provocación gradual en una paciente con anafilaxia después de una vacunación previa. Arch Argent Pediatr 2017;115(2):e89-e91.

\section{INTRODUCCIÓN}

La alergia al huevo es una de las alergias alimentarias más frecuentes durante la niñez, junto con la alergia a la leche de vaca. ${ }^{1}$ La vacuna triple viral (VTV), contra el sarampión, la rubéola y las paperas, es parte del calendario de vacunación

a. İzmir Kâtip Çelebi Üniversitesi, Facultad de Medicina, Departamento de Pediatría, División de Alergia e Inmunología Pediátricas, Hospital Universitario y de Investigación de Tepecik, Departamento de Pediatría. Esmirna, Turquía.

b. Hospital Universitario y de Investigación de Tepecik,

Departamento de Pediatría. Esmirna, Turquía.

Correspondencia:

Dra. Tuba Tuncel: ttuncel@yahoo.com.tr

Financiamiento: Ninguno.

Conflicto de intereses: Ninguno que declarar.

Recibido: 23-5-2016

Aceptado: 11-10-2016 pediátrica y contiene proteína de huevo. ${ }^{2}$ Se ha demostrado que la VTV es segura y eficaz, y las reacciones anafilácticas son aisladas. ${ }^{3,4} \mathrm{Si}$ bien se ha informado que la VTV es también segura para los pacientes con alergia al huevo, algunos tuvieron anafilaxia después de su administración. ${ }^{5}$ En este artículo, presentamos el caso de la administración satisfactoria de la VTV mediante el aumento gradual de la dosis a una paciente que tuvo anafilaxia después de la aplicación de la VTV.

\section{A propósito de un caso}

A la paciente se la evaluó en su primera consulta al departamento de alergias a los 9 meses de vida. Los antecedentes de la paciente indicaban que, a los 5 meses de vida, había tenido enrojecimiento e hinchazón alrededor de los labios y erupción pruriginosa en los ojos, el rostro y el cuerpo, sibilancias y tos, después de consumir leche maternizada que contenía leche de vaca. Se informó que había presentado reacciones similares después de consumir yogurt y huevo en distintos momentos. La examinó un pediatra y se le recomendó una dieta sin huevo ni leche, pero no se realizaron análisis de laboratorio. Su familia no le había dado alimentos con leche ni huevo, y la paciente no había presentado nuevos inconvenientes. A los 9 meses de vida, se le administró la VTV; a los 10 minutos tuvo enrojecimiento, prurito, sibilancias y dificultad respiratoria. Se la nebulizó con albuterol y epinefrina en la sala de emergencias. Uno de los médicos de la sala de emergencias derivó a la paciente a nuestra clínica debido a sospecha de alergia alimentaria y reacción alérgica posterior a la vacunación. Durante la consulta, no presentaba síntomas, y el examen físico era normal. El hemograma completo y el análisis bioquímico de la sangre eran normales. Las reacciones cutáneas y respiratorias en los antecedentes de la paciente, causadas por la leche, el huevo y la VTV, se consideraron compatibles con anafilaxia. Se le realizó una prueba intraepidérmica y se observó 
una zona indurada de $3 \times 3 \mathrm{~mm}$ con el control positivo, de $5 \times 5 \mathrm{~mm}$ con la yema de huevo, de $7 \times 7 \mathrm{~mm}$ con la clara de huevo y de $5 \times 5 \mathrm{~mm}$ con la leche de vaca. El resultado de la prueba intraepidérmica con gelatina fue negativo. A la paciente se le diagnosticó alergia al huevo y a la leche de vaca sin provocación debido a la anafilaxia después de la ingesta de alimentos y a los antecedentes y los hallazgos de laboratorio que coincidían con alergia alimentaria. A la paciente se le indicó dieta sin leche ni huevo. Se instruyó a los padres sobre cómo leer las etiquetas de los alimentos y también se le recetó un autoinyector de epinefrina. Cuando la paciente cumplió 1 año, se le realizaron nuevamente pruebas intraepidérmicas, y se observó que continuaba con sensibilidad al huevo y la leche. Se evaluó a la paciente para determinar si podía recibir la segunda dosis de la VTV, pautada al año de vida. Se planificó la administración de la VTV después de realizar pruebas de alergia con la solución de la vacuna. Una vez que se observó que la prueba intraepidérmica con la solución de la VTV (1:1) (Priorix ${ }^{\circledR}$ de Glaxo Smith Kline) era negativa, se realizó una prueba intradérmica, la cual fue positiva y produjo una zona indurada de $5 \times 5 \mathrm{~mm}$. Por ello, se decidió administrar la vacuna de manera gradual. Se administró el total de los $0,5 \mathrm{ml}$ de la vacuna en dosis de 0,01 $\mathrm{ml}, 0,04 \mathrm{ml}, 0,10 \mathrm{ml}, 0,15 \mathrm{ml}$ y $0,20 \mathrm{ml}$ cada 20 minutos. No se observó ninguna reacción tras la administración de la vacuna en cinco dosis.

\section{DISCUSIÓN}

Las alergias al huevo y la leche de vaca son las alergias alimentarias más frecuentes en los niños. ${ }^{1}$ Evitar el consumo de los alimentos que causan la reacción alérgica es la base del tratamiento de los pacientes con alergias alimentarias. ${ }^{6}$ Se ha analizado la administración de vacunas que contienen huevo, en particular la VTV, a pacientes con alergia al huevo. En publicaciones previas, se recomendaba la realización de una prueba cutánea con la vacuna seguida de la vacunación con dosis en aumento. ${ }^{7}$ Sin embargo, los estudios posteriores indicaban que la VTV es segura para los niños con alergia al huevo, y que la gelatina podría ser la causante de las reacciones. ${ }^{8-11}$ Actualmente, la recomendación aceptada es que la VTV debe administrarse en una dosis única bajo supervisión médica. ${ }^{2,4,12}$ No obstante, algunos pacientes tienen anafilaxia después de recibirla. ${ }^{4,13}$ En el caso de nuestra paciente, con base en los antecedentes y los análisis de laboratorio, se consideró que el huevo presente en la VTV podría haber causado la anafilaxia que tuvo después de la vacunación.

Hasta 2011, en Turquía, la VTV se administraba en dos dosis, a los 12 meses y a los 6 años de edad. ${ }^{14}$ Luego, a partir de la inmigración de países vecinos hacia Turquía, se produjo un aumento de los casos de sarampión; por lo que se comenzó a administrar la vacuna a los 9 meses de vida. La vacuna se repite a los 12 meses ya que no brinda inmunidad suficiente. Nuestra paciente tuvo anafilaxia después de recibir la VTV a los 9 meses. El riesgo de recurrencia de la anafilaxia con la segunda dosis era una realidad debido a que el período entre ambas dosis era muy breve y la paciente no había desarrollado tolerancia. No obstante, se decidió administrar la segunda dosis de la VTV una vez considerado el riesgo de sarampión. Si bien la anafilaxia después de una vacunación previa es una contraindicación, también se consideró la recomendación de administrar la vacuna de manera gradual después de una prueba cutánea. ${ }^{15}$ Sin embargo, no existe información detallada en las publicaciones. Por este motivo, se realizaron pruebas intraepidérmicas e intradérmicas con la solución de la VTV; el resultado de la prueba intradérmica fue positivo. Por consiguiente, se administró la vacuna en cinco dosis en total. No se observaron inconvenientes después de la vacunación.

Podría ocurrir anafilaxia después de la administración de la VTV en los pacientes con alergia al huevo, como en nuestra paciente. Por lo tanto, la vacuna debe administrarse en un centro donde sea posible tratar la anafilaxia y donde los pacientes puedan permanecer bajo observación después de recibirla. Si se produce anafilaxia, la provocación gradual podría ser una opción para la administración de dosis futuras. Se presenta este caso para destacar que la VTV podría administrarse en dosis divididas sin que se produzca una reacción, incluso en los pacientes con anafilaxia después de la vacunación.

\section{REFERENCIAS}

1. Nwaru BI, Hickstein L, Panesar SS, Roberts G, et al. EAACI Food Allergy and Anaphylaxis Guidelines Group. Prevalence of common food allergies in Europe: a systematic review and meta-analysis. Allergy 2014;69(8):992-1007.

2. American Academy of Pediatrics. Measles. En: Pickering L ed. Red Book. 2012. Report of The Committee on Infectious Disease. $2^{\text {th }}$ ed. ELK grove Village, IL: American Academy of Pediatrics; 2012.Págs.489-500.

3. D'Souza RM, Campbell-Lloyd S, Isaacs D, Gold M, et al. Adverse events following immunisation associated with the 1998 Australian Measles Control Campaign. Commun Dis Intell 2000;24(2):27-33. 
4. McLean HQ, Fiebelkorn AP, TemteJL, Wallace GS, Centers for Disease Controland Prevention. Prevention of measles, rubella, congenital rubella syndrome, and mumps, 2013: summary recommendations of the Advisory Committee on Immunization Practices (ACIP). MMWR Recomm Rep 2013;62(RR-04):1-34.

5. Firıncı F, Uysal P, Tuncel T, Arikan Ayyildiz Z, et al. Yumurta allerjisi olan bir olguda kızamık-kızamıkçık-kabakulak aşısı sonrası anafilaksi (poster presentation p17) Turk Pediatri Ars 2010;45:175.

6. Sampson HA, Aceves S, BockSA, James J, et al. Food allergy: a practice parameter update-2014. J Allergy Clin Immunol 2014;134(5):1016-25.e43.

7. Herman JJ, Radin R, Schneiderman R. Allergic reaction to measles (rubeola) vaccine in patients hypersensitive to egg protein. J Pediatr 1983;102(2):196-9.

8. Freigang B, Jadavji TP, Freigang DW. Lack of adverse reactions to measles, mumps, and rubella vaccine in eggallergic children. Ann Allergy 1994;73(6):486-8.

9. James JM, Burks AW, Roberson PK, Sampson HA. Safe administration of the measles vaccine to children allergic to eggs. N Engl J Med 1995;332(19):1262-6.
10. Patja A, Mäkinen-Kiljunen S, Davidkin I, Paunio M, et al. Allergic reactions to measles-mumps-rubella vaccination. Pediatrics 2001;107(2):E27.

11. Cerecedo CarballoI, DieguezPastor MC, BartoloméZavala B, Sánchez Cano M, et al. Safety of measles-mumpsrubella vaccine (MMR) in patients allergic to eggs. Allergol Immunopathol (Madr) 2007;35(3):105-9.

12. Khakoo GA, Lack G. Recommendations for using MMR vaccine in children allergic to eggs. BMJ 2000;320(7239): 929-32.

13. Yavuz ST, Sahiner UM, Sekerel BE, Tuncer A, et al. Anaphylactic reactions to measles-mumps-rubella vaccine in three children with allergies to hen's egg and cow's milk. Acta Paediatr 2011;100(8):e94-6.

14. Sağlık Bakanlığı Temel Sağlık Hizmetleri Genel Müdürlüğü, Genişletilmiş Bă̆ış̧ılama Programı Genelgesi: 13.03.2009/7941 [Acceso: 12 de diciembre de 2015]. Disponible en: www.saglik. gov.tr

15. National Advisory Committee on Immunization (NACI). Supplementary statement MMR vaccine and anaphylactic hypersensitivity to egg or egg-related antigens. Can Commun Dis Rep 1996;22(14):113-5. 